\title{
Efficacy of triple therapies including ionising radiation, agonistic TRAIL antibodies and cisplatin
}

\author{
MAXIMILIAN NIYAZI ${ }^{1}$, PATRIZIA MARINI ${ }^{1}$, PETER T. DANIEL ${ }^{2}$, ROBIN HUMPHREYS $^{3}$, \\ VERENA JENDROSSEK ${ }^{4}$ and CLAUS BELKA ${ }^{5}$
}

\begin{abstract}
${ }^{1}$ CCC Tübingen, Department of Radiation Oncology, Hoppe-Seyler-Strasse 3, 72076 Tübingen;
${ }^{2}$ Clinical and Molecular Oncology, Charité, Campus Berlin-Buch Humboldt University, Lindberger Weg 80, 13125

Berlin-Buch, Germany; ${ }^{3}$ Oncology Research Department, Human Genome Sciences Inc., 14200 Shady Grove Road,

Rockville, MD 20850, USA; ${ }^{4}$ Department of Molecular Cell Biology, Virchowstrasse 173, 45122 Essen; ${ }^{5}$ Department of

Radiation Oncology, Ludwig-Maximilians-University München, Marchioninistrasse 15, 81373 München, Germany
\end{abstract}

Received February 19, 2009; Accepted March 5, 2009

DOI: 10.3892/or_00000374

\begin{abstract}
The detection of molecular targeted agents is a milestone in cancer treatment. Despite the achievements, the efficacy of single targeted agents in combination with radiotherapy is limited by putative treatment resistance. We therefore tested a rationally designed triple therapy consisting of an agonistic antibody against either TRAIL-R1 (mapatumumab/HGS-ETR1) or TRAIL-R2 (lexatumumab/HGSETR2) in combination with the established chemotherapeutic drug cisplatin in a panel of solid tumour cell lines derived from head and neck as well as colorectal carcinomas. Induction of apoptosis after monotherapy, double or triple treatment was determined in $\mathrm{FaDu}$ (squamous cancer cell line of the head and neck), Colo205 and HCT116 cells (colorectal adenocarcinoma cell lines) by Hoechst 33342 stain. Double and triple therapies were compared using analysis of variance followed by post hoc tests. The degree of interaction was determined by 3D-isobologram analysis. A knockout variant of HCT116 was used to examine Baxdependence of the triple therapy to gain insight into the underlying molecular signaling pathways possibly responsible for the observed effects. Dose-response relationships revealed different baseline activities of the modalities dependent on cell type. Triple therapy was more effective than double
\end{abstract}

Correspondence to: Dr Claus Belka, Department of Radiation Oncology, Ludwig-Maximilians-University München, Marchioninistrasse 15, 81373 München, Germany

E-mail: claus.belka@med.uni-muenchen.de

Abbreviations: TRAIL, TNF- $\alpha$-related apoptosis-inducing ligand; $\mathrm{RT}$, radiotherapy; IR, irradiation; cisPt, cisplatin; $\mathrm{mAb}$, monoclonal antibody; Bcl-2, B-cell lymphoma 2; Bax, Bcl-2-associated X protein; wt, wild-type; TNF- $\alpha$, tumor necrosis factor- $\alpha$; CD95-L, CD95 ligand; COX-2, cyclooxygenase-2; HIF-1, hypoxia-inducible factor- 1 ; NF- $\mathrm{\kappa B}$, nuclear factor- $\mathrm{kB}$; Akt/PKB, protein kinase $\mathrm{B}$

Key words: radiotherapy, TRAIL antibodies, mapatumumab, lexatumumab, cisplatin, triple therapy therapy in most cases according to the induction of apoptosis. Furthermore, a synergistic efficacy of the triple therapy was demonstrated in a subset of tumour cell lines. The efficacy of this multimodal approach was highly dependent on the presence of Bax. Our data suggest that targeted agents can be effectively added to existing multimodal therapy approaches which might open new perspectives in radiation oncology.

\section{Introduction}

Treatment of many solid cancer types currently relies on the combination of conventional cytotoxic drugs with ionising radiation, e.g. in case of lung cancer $(1,2)$, rectal cancer (3), esophageal cancer $(4)$, cancer of the anal canal $(5,6)$ and head and neck cancer (7).

Additionally, several targeted approaches in combination with radiation have been and are tested in preclinical and early clinical settings, including HIF-1 blockade (8), COX-2 blockade $(9,10)$, inhibition of tyrosine kinase signaling (11), as well as interference with NF- $\mathrm{KB}$ (12) and ras (13) or Akt/PKB-signaling (14).

Up to now, many new drugs have either been tested together with cytostatic agents or ionising radiation. However, scarce data are available on the efficacy of targeted drugs within the framework of already established multimodal settings (reviewed in ref. 15).

Previously we showed that combination of radiotherapy and the human agonistic TRAIL antibodies mapatumumab/ HGS-ETR1 or lexatumumab/HGS-ETR2 alone was effective in adeno- and squamous cell carcinoma cell systems (16). TRAIL was initially characterized as an apoptosis inducing ligand with homology to TNF- $\alpha$ and CD95-L (17). Soon after the initial description, it became clear that TRAIL was an apoptosis inducer with a high specificity for malignant tumour cell systems $(18,19)$. The propensity for malignant cells is closely connected to the physiological role of TRAIL as part of the immune tumour surveillance system (reviewed in ref. 20).

Agonistic antibodies targeting TRAIL-Receptors 1 (TRAIL-R1) or TRAIL-R2 are currently undergoing clinical 
FaDu

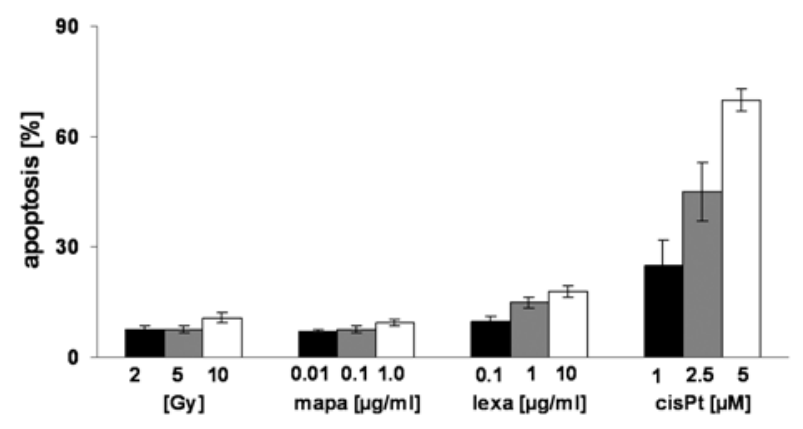

HCT116

Bax wt

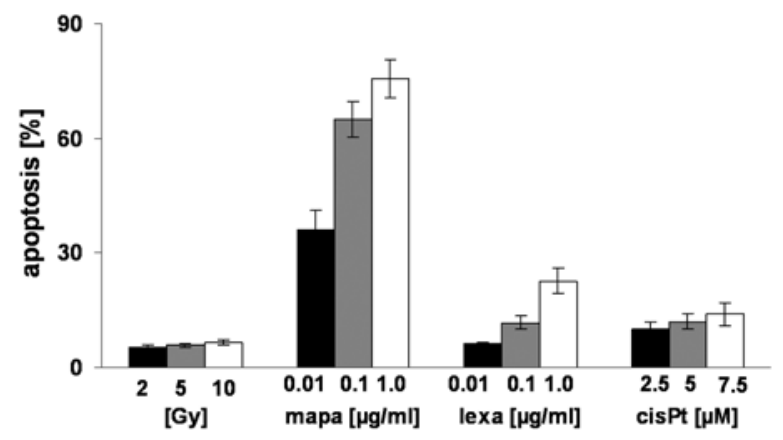

Colo 205

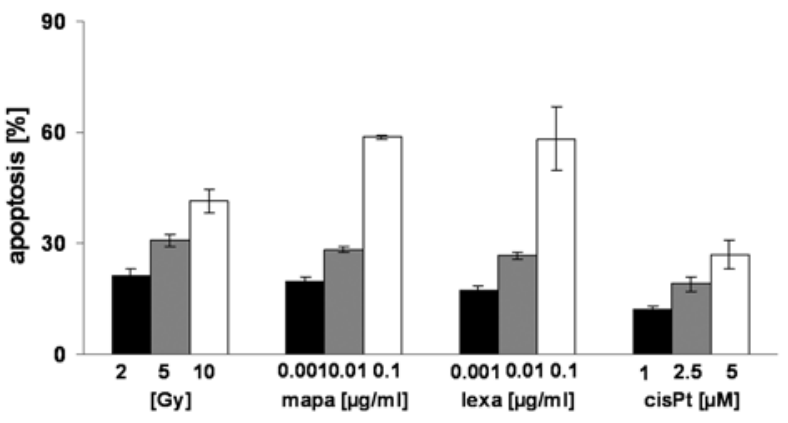

HCT116 Bax $^{-1-}$

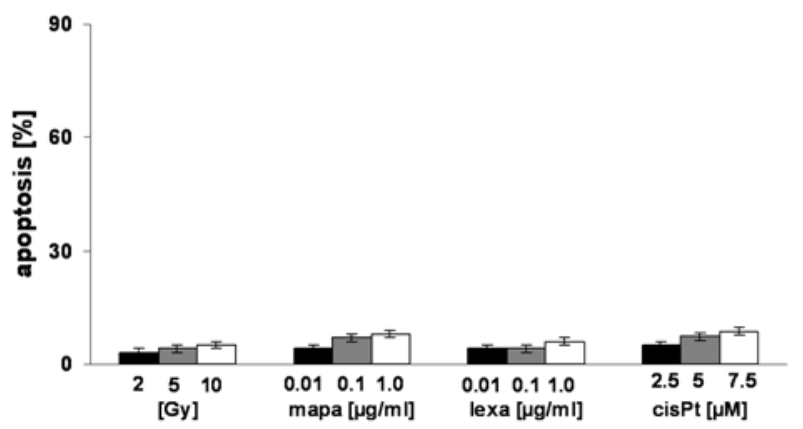

Figure 1. Basic dose-response relationships for monotherapies. Apoptosis was determined by fluorescence microscopic evaluation of Hoechst 33342 stained $\mathrm{FaDu}$, Colo205, HCT116 Bax wt and HCT116 Bax ${ }^{-/}$cells. Treatment with three different irradiation doses $(2,5,10 \mathrm{~Gy})$, TRAIL-mAb concentrations ranging from 0.001 to $1.0 \mu \mathrm{g} / \mathrm{ml}$ (mapatumumab) or 0.001 to $10 \mu \mathrm{g} / \mathrm{ml}$ (lexatumumab) and finally cisplatin concentrations ranging from 1.0 to $7.5 \mu \mathrm{M}$. Apoptotic rates were determined $48 \mathrm{~h}$ (cisplatin) or $36 \mathrm{~h}$ after radiotherapy/TRAIL-R stimulation (FaDu, Colo205) and $36 \mathrm{~h}$ (cisplatin) or $24 \mathrm{~h}$ after radiotherapy/TRAIL-R stimulation (HCT116 Bax wt and $\mathrm{Bax}^{-/}$). Data represent means of three independent experiments; bars \pm SEM.

phase I and phase II testing. Up to now, no major toxicities have been reported (De Bono JS, et al, 16th EORTC-NCIAACR Symposium on Molecular Targets and Cancer Therapeutics, Geneva, Switzerland, 2004; Attard G, et al, AACR-NCI-EORTC International Conference on Molecular Targets and Cancer Therapeutics, Philadelphia, PA, USA, 2005; Kanzler S, et al, ECCO 13 - the European Cancer Conference, Paris, France, 2005). Since cisplatinum-based radiochemotherapy protocols may be regarded as therapeutic standard for many cancer entities (21), we tested how much inclusion of a third agent, namely agonistic TRAIL antibodies, could improve the results in vitro.

Altogether, there are very few in vitro and in vivo studies which were performed to test combinations of radiochemotherapy with additional modalities (22-26). Since an optimal eradication of cancer cells is most likely achieved when more than one non-cross-resistant modality is combined, we speculated that the combination of three non-cross-resistant and even positively interacting treatment modalities would be of high value for cancer treatment.

In order to test this hypothesis we determined the efficacy of a triple combination of agonistic TRAIL antibodies, cisplatin and radiation in several solid tumour cell systems and tried to gain insight into the underlying mechanisms using genetically defined cell lines.

\section{Materials and methods}

Chemicals and drugs. The agonistic monoclonal TRAIL-R1/2 antibodies mapatumumab/HGS-ETR1 and lexatumumab/ HGS-ETR2 were obtained from Human Genome Sciences, Rockville, MD, USA. All other chemicals were obtained from Sigma Aldrich (Steinheim, Germany) unless otherwise specified.

Cell culture. The colorectal cell line Colo205 and the squamous cell line FaDu were purchased from ATCC (Bethesda, MD, USA), the colorectal cell lines HCT116 Bax wt and $\mathrm{Bax}^{-/}$were kindly provided by P.T. Daniel (Charité, Berlin, Germany). Colo205 cells were grown in RPMI-1640 medium supplemented with $10 \%$ fetal calf serum, $100 \mathrm{U} / \mathrm{ml}$ penicillin and $100 \mu \mathrm{g} / \mathrm{ml}$ streptomycin (Invitrogen-Gibco, Karlsruhe, Germany), FaDu cells in MEM and HCT116 Bax $\mathrm{wt} / \mathrm{Bax}^{-/-}$in McCoy's 5A medium (both by Invitrogen-Gibco). Tumour cells were maintained in a humidified incubator at $37^{\circ} \mathrm{C}$ and $5 \% \mathrm{CO}_{2}$.

Irradiation. Irradiation (IR) was performed with an Elekta linear accelerator using $6 \mathrm{MV}$ photons and a dose rate of 4 Gy per min. Tumour cells were irradiated directly in cell culture flasks at room temperature. 
Table I. Comparison between double and triple therapies.

\begin{tabular}{|c|c|c|}
\hline & $\mathrm{X}=$ mapa & $X=$ lexa \\
\hline \multicolumn{3}{|l|}{$\mathrm{FaDu}$} \\
\hline $\mathrm{RT}+$ cisPt vs. triple & 0.006 & 0.001 \\
\hline $\mathrm{RT}+\mathrm{X}$ vs. triple & $\mathrm{p}<0.001$ & $\mathrm{p}<0.001$ \\
\hline \multicolumn{3}{|l|}{ Colo 205} \\
\hline $\mathrm{RT}+$ cisPt vs. triple & 0.004 & $\mathrm{p}<0.001$ \\
\hline $\mathrm{RT}+\mathrm{X}$ vs. triple & $\mathrm{p}<0.001$ & $\mathrm{p}<0.001$ \\
\hline \multicolumn{3}{|l|}{ HCT116 Bax wt } \\
\hline $\mathrm{RT}+$ cisPt vs. triple & $\mathrm{p}<0.001$ & $\mathrm{p}<0.001$ \\
\hline RT + X vs. triple & ns $(\mathrm{p}=0.7)$ & $\mathrm{p}<0.001$ \\
\hline \multicolumn{3}{|l|}{ HCT116 $\mathrm{Bax}^{-/}$} \\
\hline $\mathrm{RT}+$ cisPt vs. triple & $\mathrm{ns}(\mathrm{p}=1.0)$ & ns $(\mathrm{p}=0.059)$ \\
\hline RT + X vs. triple & ns $(\mathrm{p}=0.991)$ & ns $(\mathrm{p}=0.084)$ \\
\hline \multicolumn{3}{|c|}{$\begin{array}{l}\text { A one-way ANOVA was carried out to discover differences between } \\
\text { different treatment modalities and to compare double and triple } \\
\text { therapies corresponding to the treatment schemes in Fig. } 2 \text {. The given } \\
\text { p-values are results of Tukey post hoc tests. For FaDu cells triple } \\
\text { therapies were superior to double therapies consisting of radio- } \\
\text { therapy and cisplatin in a very significant way and the difference } \\
\text { compared to mapa-/lexatumumab-based combined therapies } \\
\text { was highly significant (borderline in one case). In Colo205 cells, } \\
\text { mapatumumab-based triple therapy was superior to cisplatinum- } \\
\text { based radiochemotherapy in a very significant manner, the other } \\
\text { comparisons yielded highly significant results. In HCT116 wt cells, } \\
\text { triple therapies were better (highly significant) than double therapies } \\
\text { except for the comparison between mapatumumab-based triple } \\
\text { therapy and radiotherapy and mapatumumab which was not signi- } \\
\text { ficant. In HCT116 Bax }{ }^{-/-} \text {cells there were no significant differences } \\
\text { between double and triple therapies. }\end{array}$} \\
\hline
\end{tabular}

Determination of apoptosis. Cell death was analysed by fluorescence microscopy upon staining of the cells with Hoechst 33342 (Calbiochem, Schwalbach, Germany). In brief, cells were incubated for $15 \mathrm{~min}$ with Hoechst $33342(1.5 \mu \mathrm{M})$ and cell morphology was then determined by fluorescence microscopy. Cells were analysed with 40-fold magnification and documented using a CCD camera device (Zeiss Axiocam MRm).

Apoptotic cells (blue stained nuclei with apoptotic nuclear morphology) were quantified by cell counting. Each well was counted at three different view points in double controls.

Statistical analysis. One-way analysis of variance (ANOVA) was performed to compare different treatment modalities using SPSS ${ }^{\circledR}$ 16.0, SPSS Inc., Illinois, USA. Tukey post hoc tests were used to compare special treatments. $\mathrm{p}<0.001$ was called 'highly significant', $\mathrm{p}<0.01$ 'very significant' and $\mathrm{p}<0.05$ 'significant'.

In order to determine the degree of interaction (additive, subadditive or synergistic) between cisplatin, TRAIL-R stimulation and ionising radiation a 3D-isobologram analysis was performed (27). Mathematica 5.2, Wolfram Research
(Friedrichsdorf, Germany) was used to conduct necessary calculations.

As a standard statistical test for isobologram analysis does not exist so far, it is though possible to calculate a new isobologram which corresponds to the lower limit of the $95 \%$ isoeffect confidence interval. If the triple therapy remains synergistic, the synergistic effect may be called 'significant'.

\section{Results}

Monotherapy characteristics. In a first subset of experiments we determined basic dose-response relationships for apoptosis induction for the individual cell death trigger by evaluation of Hoechst stained cells. Since a maximum level of apoptosis induction was reached $36 \mathrm{~h}$ ( $\mathrm{FaDu}$ and Colo205 cells) or $24 \mathrm{~h}$ (HCT116 Bax wt and $\mathrm{Bax}^{-/}$) after the respective treatment, the subsequent analyses were restricted to these time-points. Administration of cisplatin was carried out $12 \mathrm{~h}$ prior to irradiation and/or antibody treatment. In general, all cell systems displayed different baseline apoptotic rates after treatment with the given trigger (Fig. 1).

In $\mathrm{FaDu}$ cells maximum levels of apoptosis induction of $18 \%$ after TRAIL-R2 stimulation (lexatumumab, $10 \mu \mathrm{g} / \mathrm{ml}$ ), $11 \%$ after irradiation (10 Gy) and $70 \%$ after cisplatin treatment $(5 \mu \mathrm{M})$ were observed (Fig. 1, FaDu). Colo205 cells were more sensitive to irradiation and TRAIL-R stimulation: a level of apoptosis of $58 \%$ was observed after TRAIL-R stimulation (mapatumumab and lexatumumab, each 0.1 $\mu \mathrm{g} / \mathrm{ml}), 42 \%$ after irradiation (10 Gy), but with $27 \%$ apoptosis Colo205 cells were less sensitive to cisplatin $(5 \mu \mathrm{M})$ treatment (Fig. 1, Colo205).

In HCT116 Bax wt and HCT116 $\mathrm{Bax}^{-/-}$cells induction of apoptosis with up to $10 \mathrm{~Gy}$ or $10 \mu \mathrm{M}$ cisplatin was each below 10/20\%, indicating Bax-independence of radiation and cisplatin-induced cell death. However, mapatumumab and lexatumumab killed 76 and $23 \%$ of HCT116 Bax wt cells, respectively. In contrast, $\mathrm{HCT} 116 \mathrm{Bax}^{-/}$cells showed complete resistance to mapatumumab and lexatumumab-induced cell death (for maximum doses 8 and 6\%, respectively) compared to its wild-type matching part, indicating Bax-dependence of TRAIL-R triggered apoptosis (Fig. 1, HCT116 Bax wt and $\left.\mathrm{Bax}^{-/-}\right)$.

Combination of cisplatin with TRAIL-R stimulation and irradiation increases cell death. After determining the basic dose-response relationships the efficacy of the potential combinations was tested. In this regard only sub-maximally active drug concentrations or radiation doses were analysed.

In accordance with previous findings, the kinetics of cisplatin induced cell death is slower when compared to TRAIL-induced apoptosis. Thus, cisplatin was added $12 \mathrm{~h}$ prior to combined treatment with irradiation and mapalexatumumab whereas the analysis was carried out $24 \mathrm{~h}$ (HCT116 Bax wt and $\left.\mathrm{Bax}^{-/}\right)$or $36 \mathrm{~h}$ (FaDu, Colo205) later. In both $\mathrm{FaDu}$ and Colo205 cell systems cell death induction after triple treatment was enhanced when compared to each single treatment or double combination (Fig. 2, Table I).

In FaDu cells, apoptosis rates of up to $87 \%$ were measured after combined treatment with $5 \mathrm{~Gy}, 5 \mu \mathrm{M}$ cisplatin and $0.1 \mu \mathrm{g} / \mathrm{ml}$ mapatumumab, whereas single treatments only 
mapa
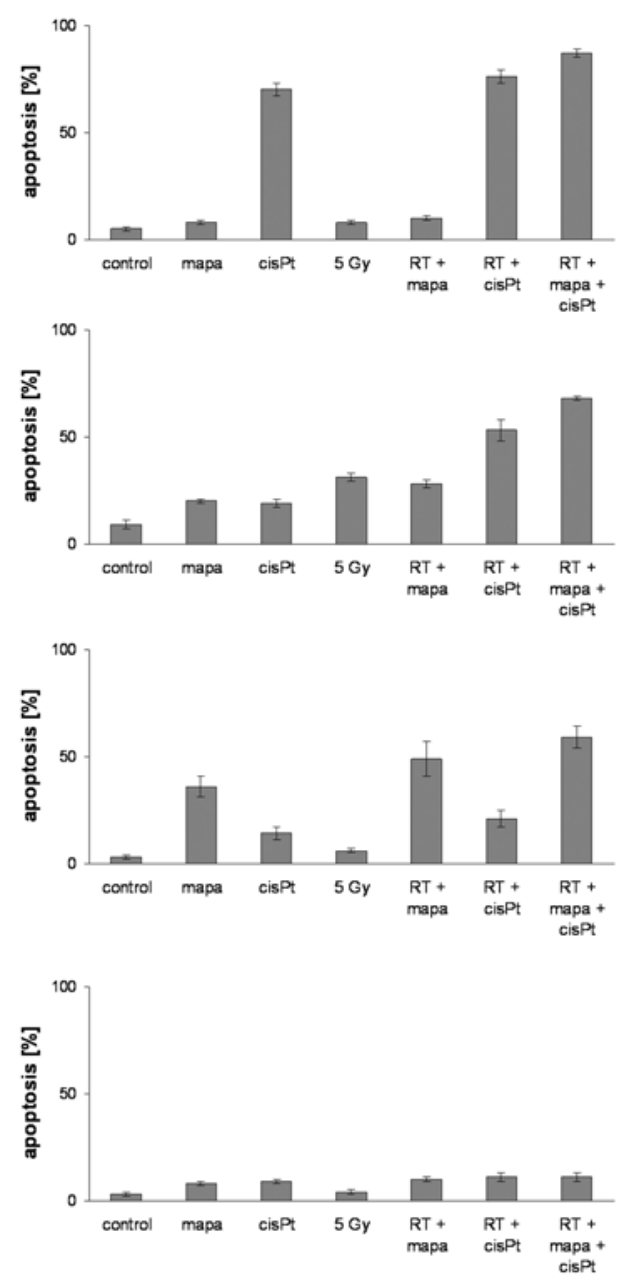

lexa
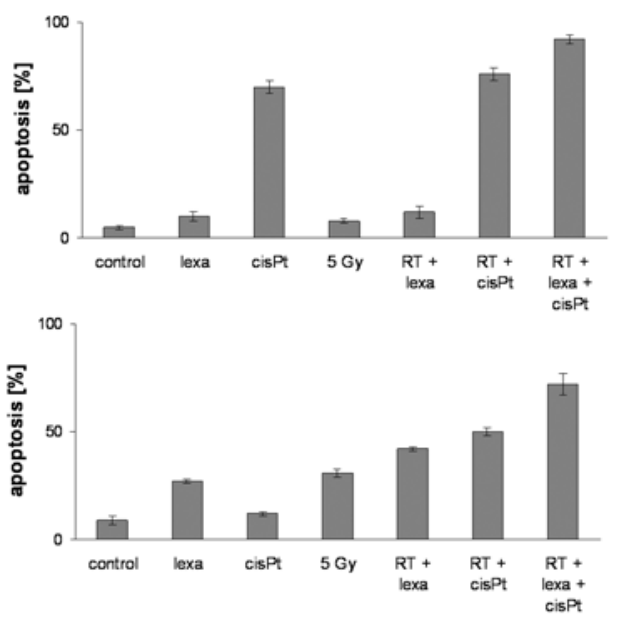

Colo 205

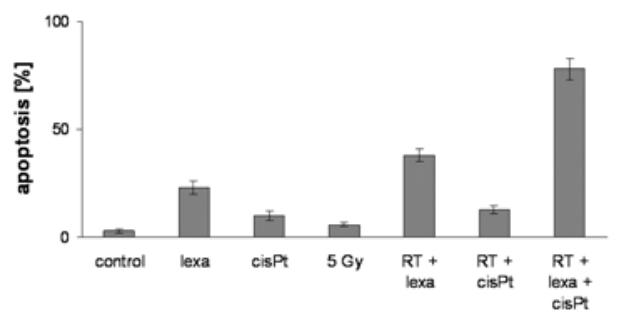

\section{HCT116 \\ Bax wt}

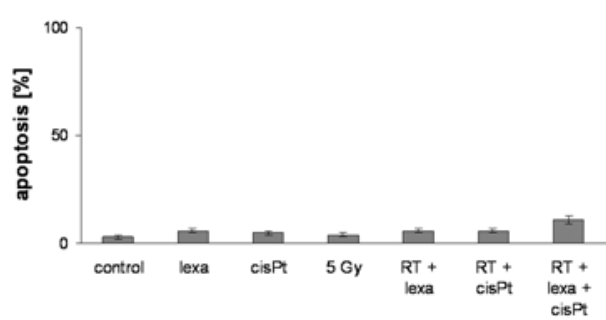

Figure 2. Induction of apoptosis after single, double and triple therapy. Data represent means of three independent experiments; bars \pm SEM. Left panel, level of apoptosis in cells treated with double or triple combinations of irradiation, mapatumumab (mapa) and/or cisplatin (cisPt). FaDu cells were treated with $5 \mathrm{~Gy}, 0.1 \mu \mathrm{g} / \mathrm{ml}$ mapatumumab and $5 \mu \mathrm{M}$ cisplatin, Colo205 cells with $5 \mathrm{~Gy}, 0.001 \mu \mathrm{g} / \mathrm{ml}$ mapatumumab and $2.5 \mu \mathrm{M}$ cisplatin. HCT116 Bax wt cells were treated with $5 \mathrm{~Gy}, 0.01 \mu \mathrm{g} / \mathrm{ml}$ mapatumumab and $7.5 \mu \mathrm{M}$ cisplatin and HCT116 Bax $^{-/-}$with $5 \mathrm{~Gy}, 1 \mu \mathrm{g} / \mathrm{ml}$ mapatumumab and $7.5 \mu \mathrm{M}$ cisplatin. Right panel, level of apoptosis in cells treated with double or triple combinations containing lexatumumab (lexa). FaDu cells were treated with $5 \mathrm{~Gy}, 0.1 \mu \mathrm{g} / \mathrm{ml}$ lexatumumab and $5 \mu \mathrm{M}$ cisplatin, Colo205 cells with $5 \mathrm{~Gy}, 0.01 \mu \mathrm{g} / \mathrm{ml}$ lexatumumab and $1 \mu \mathrm{M}$ cisplatin. HCT116 Bax wt cells were treated with $5 \mathrm{~Gy}$, $1 \mu \mathrm{g} / \mathrm{ml}$ lexatumumab and $2.5 \mu \mathrm{M}$ cisplatin and compared to HCT116 $\mathrm{Bax}^{-/-}$(also $5 \mathrm{~Gy}, 1 \mu \mathrm{g} / \mathrm{ml}$ lexatumumab and $2.5 \mu \mathrm{M}$ cisplatin).

caused rates of 8,70 or $8 \%$, respectively. This triple therapy was superior to radiotherapy and cisplatin $(\mathrm{p}=0.006)$ and radiotherapy and mapatumumab $(\mathrm{p}<0.001)$ in a very/highly significant manner (Table I). Using lexatumumab instead of mapatumumab the rate even increased to $92 \%$ whereas single treatments revealed 10, 70 or $8 \%$, respectively (Fig. 2, FaDu). In this case, the triple approach compared to both double therapies was better in a highly significant manner $(\mathrm{p}<0.001$, borderline very/highly significant in the cisplatinum case: $\mathrm{p}=0.001$, Table I).

In Colo205 cells apoptotic rates up to $68 \%(\mathrm{p}=0.004$ compared to RT and cisPt, $\mathrm{p}<0.001$ for RT and mapatumumab, Table I) or $72 \%$ ( $<<0.001$ compared to both double therapies, Table I) were measured after combined treatment with $5 \mathrm{~Gy}$, $2.5 \mu \mathrm{M}$ cisplatin and $0.001 \mu \mathrm{g} / \mathrm{ml}$ mapatumumab or $5 \mathrm{~Gy}$, $1 \mu \mathrm{M}$ cisplatin and $0.01 \mu \mathrm{g} / \mathrm{ml}$ lexatumumab, recpectively. Single treatments only caused rates of $28,19 \%(2.5 \mu \mathrm{M}$ cisplatin), 12\% (1 $\mu \mathrm{M}$ cisplatin), 20\% (mapatumumab) and $27 \%$ (lexatumumab), respectively (Fig. 2, Colo205).
In order to detect the molecular basis of the improved efficacy of a triple treatment including cisplatin, anti-TRAIL receptor antibodies and ionising radiation, we investigated the involvement of Bax, a pro-apoptotic Bcl-2 family member that acts via the mitochondrial apoptotic pathway. For this purpose, we examined the HCT116 $\mathrm{Bax}^{-/-}$cell line in which the Bax gene was knocked out by targeted gene disruption (28).

The evaluation of triple therapy experiments with HCT116 cells revealed a decrease of efficacy from 59\% apoptosis in HCT116 Bax wt cells down to $11 \%$ apoptosis in $\mathrm{Bax}^{-/-}$cells after triple therapy including mapatumumab and from $78 \%$ to $11 \%$ including lexatumumab, respectively (Fig. 1, HCT116 Bax wt and $\mathrm{Bax}^{--}$). The loss of significance for the comparison between triple therapy and double therapies is documented in Table I.

3D-isobologram analysis. In Fig. 3 the degrees of interaction in all four tested cell lines for combinations with either mapa- 

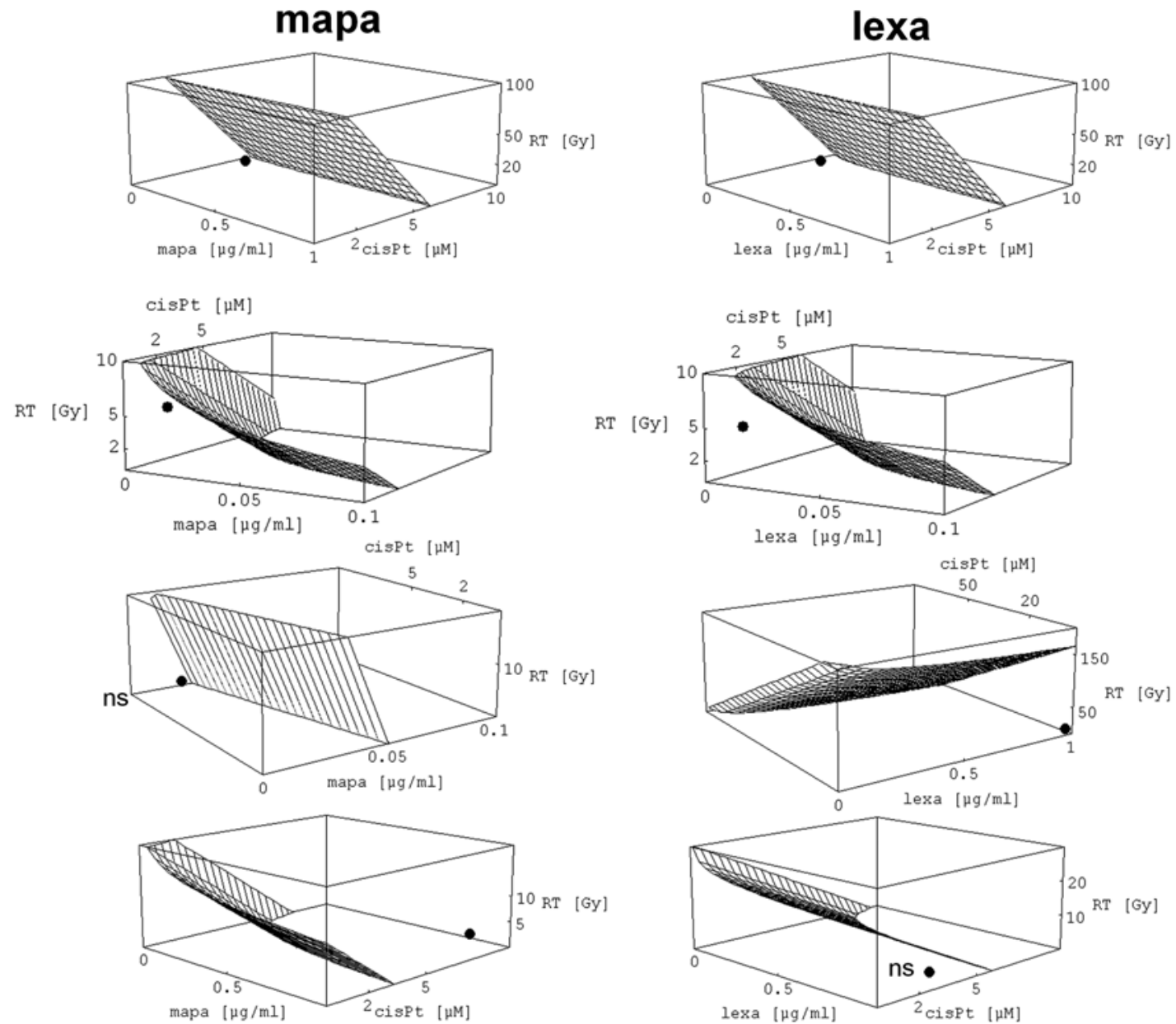

$\mathrm{FaDu}$

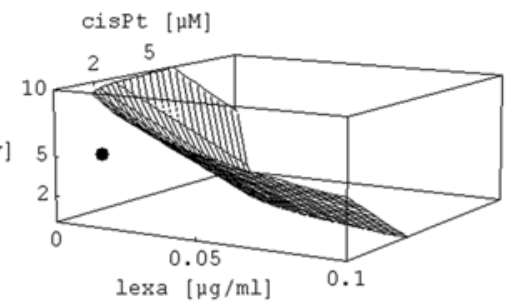

Colo 205

Figure 3. 3D-isobologram analysis of induction of apoptosis after triple therapy. Synergism is indicated if the treatment point lies within the volume limited by the first octant and the innermost surface of the 'volume of additivity'. The evaluations were performed for the triple combinations shown in Fig. 2. Left panel (combinations including mapatumumab), significant synergistic efficacy in FaDu and Colo205 cells; synergistic, but not significant efficacy in HCT116 wt cells, no synergism in HCT116 Bax ${ }^{-/}$cells; right panel (lexatumumab), again significant synergistic efficacy in FaDu and Colo205, even in HCT116 (wt) cells; no significant synergism in $\mathrm{HCT} 116 \mathrm{Bax}^{-/}$cells.

tumumab or lexatumumab are shown (doses and concentrations as before and indicated in Fig. 2).

A Cartesian coordinate system visualises the treatment phase space: the axes are labelled with the corresponding drug concentrations/irradiation doses [X, mapa-/lexatumumab $(\mu \mathrm{g} / \mathrm{ml}) ; \mathrm{Y}$, cisplatin $(\mu \mathrm{M}) ; \mathrm{Z}$, radiotherapy $(\mathrm{Gy})]$. The socalled 'point of therapy' is defined as a point which has the coordinates of the given triple therapy.

In a 3D-isobologram analysis a synergism is indicated if the treatment point lies within the volume limited by the first octant and the innermost surface of the "volume of additivity'. The construction of this volume is rather complex and described in detail (27).

For the sake of simplicity in Fig. 3 only the innermost surface is displayed. Best results were obtained in $\mathrm{FaDu}$ and Colo205 cells. In this regard, significant synergistic effects were found in both cell lines as well for both anti-bodies (Fig. 3, FaDu and Colo205, $\alpha=0.05$ ).

The response pattern was more complex when HCT116 cells were treated: using mapatumumab, triple treatments resulted in a strongly additive effect in HCT116 Bax wt cells. The level of additivity was even weaker in HCT116 $\mathrm{Bax}^{-/}$. In contrast, a triple therapy including lexatumumab was signi- ficantly synergistic for HCT116 Bax wt, but the significance was lost in HCT116 $\mathrm{Bax}^{-/-}$cells (Fig. 3, HCT116 Bax wt and $\left.\mathrm{Bax}^{-/}\right)$.

\section{Discussion}

Our data clearly suggest that TRAIL-R stimulation is able to induce additional cell death even in the setting of a classical multimodal approach combining cisplatin with ionising radiation.

ANOVA post-hoc testing revealed that triple therapies were in principle more effective than radiotherapy and cisplatin or radiotherapy and TRAIL-R stimulation.

As shown, the bio-mathematical mode of interaction was synergistic in most cases. The observed synergy refers to the efficacy of the whole triple approach compared to the calculated additive efficacy of all three treatments alone. However, a 3D-isobologram model does not allow for a final judgment as to which component of the triple approach is the driving force for the resulting synergy.

Nevertheless, we could clearly show that the presence of the pro-apoptotic Bax molecule seems to be critical and is required for an effective molecular interaction of all three 
components, e.g. it was not possible to show an enhancement of triple compared to double therapies and the synergistic effects found in HCT116 Bax wt cells disappeared in the knockout variant.

The role of apoptosis and resistance to apoptosis for the eradication of clonogenic tumour cells remains a problem of preclinical analysis $(29,30)$. However, former studies showed that drug concentrations that efficiently induced apoptosis in short-term assays were comparable to those which enhanced eradication of clonogenic tumour cells (31).

Since an increase in apoptosis induction is not necessarily translated into increased eradication of clonogenic tumour cells further work has to be done to test whether our triple therapy efficiently induces clonogenic cell death.

The high efficacy of our tested triple therapy according to different cell carcinoma systems recommends a further examination concerning clonogenic cell death and subsequently in an animal model. The experiments furthermore imply that under our conditions no molecular cross-resistance between radiation, TRAIL and cisplatin occurs.

Furthermore, our data support the assumption, that in the near future, multimodal and rationally tailored targeting strategies combined with irradiation might have an important place in oncology.

\section{Acknowledgements}

The study was supported by a grant from the Federal Ministry of Education and Research (Fö. 1548-0-0) and the Interdisciplinary Center of Clinical Research Tübingen (IZKF). We furthermore thank Stig Linder, Cancer Center Karolinska, Stockholm for helpful advice.

\section{References}

1. Vokes EE, Crawford J, Bogart J, Socinski MA, Clamon G and Green MR: Concurrent chemoradiotherapy for unresectable stage III non-small cell lung cancer. Clin Cancer Res 11: S5045-S5050, 2005.

2. Fietkau R: Concomitant radiochemotherapy of advanced nonsmall-cell lung cancer. Lung Cancer 33 (Suppl. 1): S65-S76, 2001.

3. Rodel C and Sauer R: Radiotherapy and concurrent radiochemotherapy for rectal cancer. Surg Oncol 13: 93-101, 2004.

4. Carcaterrra M, Osti MF, De Sanctis V, Caruso C, Berardi F and Enrici RM: Adjuvant radiotherapy and radiochemotherapy in the management of esophageal cancer: a review of the literature. Rays 30: 319-322, 2005.

5. Belkacemi Y, Berger C, Poortmans P, et al: Management of primary anal canal adenocarcinoma: a large retrospective study from the Rare Cancer Network. Int J Radiat Oncol Biol Phys 56: 1274-1283, 2003.

6. Ferrigno R, Nakamura RA, Dos Santos Novaes PE, et al: Radiochemotherapy in the conservative treatment of anal canal carcinoma: retrospective analysis of results and radiation dose effectiveness. Int J Radiat Oncol Biol Phys 61: 1136-1142, 2005.

7. Pignon JP, Bourhis J, Domenge C and Designe L: Chemotherapy added to locoregional treatment for head and neck squamouscell carcinoma: three meta-analyses of updated individual data. MACH-NC Collaborative Group. Meta-analysis of chemotherapy on head and neck cancer. Lancet 355: 949-955, 2000.

8. Zhong H, Chiles K, Feldser D, et al: Modulation of hypoxiainducible factor 1alpha expression by the epidermal growth factor/ phosphatidylinositol 3-kinase/PTEN/AKT/FRAP pathway in human prostate cancer cells: implications for tumor angiogenesis and therapeutics. Cancer Res 60: 1541-1545, 2000.

9. Komaki R, Liao Z and Milas L: Improvement strategies for molecular targeting: cyclooxygenase- 2 inhibitors as radiosensitizers for non-small cell lung cancer. Semin Oncol 31 : 47-53, 2004.
10. Ganswindt U, Budach W, Jendrossek V, Becker G, Bamberg M and Belka C: Combination of celecoxib with percutaneous radiotherapy in patients with localised prostate cancer - a phase I study. Radiat Oncol 1: 9, 2006

11. Baumann M, Krause M, Zips D, et al: Molecular targeting in radiotherapy of lung cancer. Lung Cancer 45 (Suppl. 2): S187-S197, 2004.

12. Pajonk F, Pajonk K and McBride WH: Inhibition of NFkappaB, clonogenicity, and radiosensitivity of human cancer cells. J Natl Cancer Inst 91: 1956-1960, 1999.

13. Cengel KA and McKenna WG: Molecular targets for altering radiosensitivity: lessons from Ras as a pre-clinical and clinical model. Crit Rev Oncol Hematol 55: 103-116, 2005.

14. Gupta AK, Cerniglia GJ, Mick R, McKenna WG and Muschel RJ: HIV protease inhibitors block Akt signaling and radiosensitize tumor cells both in vitro and in vivo. Cancer Res 65: 8256-8265, 2005.

15. Rodel C and Sauer R: Integration of novel agents into combinedmodality treatment for rectal cancer patients. Strahlenther Onkol 183: 227-235, 2007

16. Marini P, Denzinger S, Schiller D, et al: Combined treatment of colorectal tumours with agonistic TRAIL receptor antibodies HGS-ETR1 and HGS-ETR2 and radiotherapy: enhanced effects in vitro and dose-dependent growth delay in vivo. Oncogene 25: 5145-5154, 2006

17. Pitti RM, Marsters SA, Ruppert S, Donahue CJ, Moore A and Ashkenazi A: Induction of apoptosis by Apo-2 ligand, a new member of the tumor necrosis factor cytokine family. J Biol Chem 271: 12687-12690, 1996.

18. Ashkenazi A, Pai RC, Fong S, et al: Safety and antitumor activity of recombinant soluble Apo2 ligand. J Clin Invest 104: $155-162,1999$

19. Walczak H, Miller RE, Ariail K, et al: Tumoricidal activity of tumor necrosis factor-related apoptosis-inducing ligand in vivo. Nat Med 5: 157-163, 1999.

20. Marini P and Belka C: Death receptor ligands: new strategies for combined treatment with ionizing radiation. Curr Med Chem Anticancer Agents 3: 334-342, 2003.

21. Brizel DM and Esclamado R: Concurrent chemoradiotherapy for locally advanced, non-metastatic, squamous carcinoma of the head and neck: consensus, controversy, and conundrum. J Clin Oncol 24: 2612-2617, 2006.

22. Pfister DG, Su YB, Kraus DH, et al: Concurrent cetuximab, cisplatin, and concomitant boost radiotherapy for locoregionally advanced, squamous cell head and neck cancer: a pilot phase II study of a new combined-modality paradigm. J Clin Oncol 24: 1072-1078, 2006.

23. Candelaria M, Garcia-Arias A, Cetina L and Duenas-Gonzalez A: Radiosensitizers in cervical cancer. Cisplatin and beyond. Radiat Oncol 1: 15, 2006.

24. Straughn JM, Oliver PG, Zhou T, et al: Anti-tumor activity of TRA-8 anti-death receptor 5 (DR5) monoclonal antibody in combination with chemotherapy and radiation therapy in a cervical cancer model. Gynecol Oncol 101: 46-54, 2006.

25. Abou El Hassan MA, Mastenbroek DC, Gerritsen WR, Giaccone $\mathrm{G}$ and Kruyt FA: Overexpression of Bcl2 abrogates chemo- and radiotherapy-induced sensitisation of NCI-H460 non-small-cell lung cancer cells to adenovirus-mediated expression of full-length TRAIL. Br J Cancer 91: 171-177, 2004.

26. Buchsbaum DJ, Zhou T, Grizzle WE, et al: Antitumor efficacy of TRA-8 anti-DR5 monoclonal antibody alone or in combination with chemotherapy and/or radiation therapy in a human breast cancer model. Clin Cancer Res 9: 3731-3741, 2003.

27. Niyazi $M$ and Belka C: Isobologram analysis of triple therapies. Radiat Oncol 1: 39, 2006.

28. Zhang L, Yu J, Park BH, Kinzler KW and Vogelstein B: Role of BAX in the apoptotic response to anticancer agents. Science 290: 989-992, 2000.

29. Brown JM and Wouters BG: Apoptosis, p53, and tumor cell sensitivity to anticancer agents. Cancer Res 59: 1391-1399, 1999.

30. Belka C and Budach W: Anti-apoptotic Bcl-2 proteins: structure, function and relevance for radiation biology. Int J Radiat Biol 78: 643-658, 2002.

31. Rubel A, Handrick R, Lindner LH, et al: The membrane targeted apoptosis modulators erucylphosphocholine and erucylphosphohomocholine increase the radiation response of human glioblastoma cell lines in vitro. Radiat Oncol 1: 6, 2006. 